\title{
Design and Implementation of the Defense Contract Management System based on B/S structure
}

\author{
Huang Tianming \\ Defense Economics Department \\ Military Economics Academy \\ Wuhan, China, 13308630897 \\ Xc_gis@126.com
}

\author{
Xie Chao \\ Defense Economics Department \\ Military Economics Academy \\ Wuhan, China, 13971012590 \\ Xiechao188@163.com
}

\begin{abstract}
The defense contract management manual work involving multiple departments and multiple content, low efficiency and error-prone. Based on the characteristics of the defense contract management business, design and development of a defense contract management system. The system was developed based on the ASP.NET environment, the development language is $\mathrm{C} \#, \mathrm{~B} / \mathrm{S}$ architecture, the main function of the basic contract information, pay/collection progress and stamp duty information entry, maintenance and inquiries, track the progress of the contract to pay/receivables and remind. The defense contract management system greatly improves the working efficiency, with favorable results.
\end{abstract}

Keywords- contract management system; ASP.NET; Access

\section{THE BACKGROUND OF DEFENSE CONTRACT MANAGEMENT SYSTEM PROJECT}

\section{A. The current situation and insufficient of defense} contract management

Perfect contract management is an important symbol of the scientific operations of the army. However, takes a lot of resources, how to simplify the management of the contract without losing its integrity, science is an extremely important issue.

Defense contract management software to solve contract management issues must be true of the military contract operations. Management software in-depth study of the operating mode of the military contract, the successful development of the Defense contract management System "software for contract management of the army in the Defense contract management System" software on the basis of the military business information can be a seamless flow and exchange of to ensure that the information in a timely manner, a wide range of real. Contract Management is a core part of the military contract business information management, collaborative platform, Contract Management is not an isolated business management, but the integration of related project management, customer management, supplier management. Similarly, the personnel involved in contract management is not limited to contract in the ordinary sense of the administrator, but the entire staff, from the procurement staff, warehouse management, sales, R \& D personnel, project staff, finance staff to the management cadres direct or indirect impact on contract management.

China's national defense contracts in the past has been the use of manual work in the contract management, resulting in low business efficiency in the process of contract management, the contract between the various departments with longer turnaround time and error-prone.

\section{B. The benefits of defense contract management system}

For manual handling of these problems, contract management and contract management to meet the growing demand, the defense industry enterprises need to develop a fully functional on the basis of IT contract management system software, used in various departments throughout the company, to achieve contract management of intelligence and standardization to improve office efficiency, and promote the upgrading of the level of corporate information management. Based on these requirements, I independently developed a defense contract management system.

Development of the system aims to further promote defense industry enterprises to improve their internal contract management system, standardize contract management processes, and thus more timely, accurate and comprehensive reflection of the contract content, to help corporate management decisions to achieve enterprise contract management, intelligence and information sharing reduce management costs, enhance the level of internal management, improve the quality of work, and timely understanding of the work of the contract management services layer to provide first-hand information to adapt to the requirements of innovation management for corporate leadership. The advantages of contract management system are:

- Information Sharing: Contract Manager to sign a contract while the contract provides for the pay/collection and progress into the system for basic information, to achieve information sharing, improve the efficiency and accuracy of the data, reducing the other departments, especially Department of Finance and the Ministry of duplication of effort.

- Facilitate the queries and tracking: Contract Manager in real time during the execution of the contract the contract the actual pay/income shall timely entry system, to facilitate the relevant departments to query and track.

- the ease of management: leadership in real-time grasp of the basic information of the company's contract to grasp the progress of the financial pay/income paragraph, and according to various combinations of criteria queries can query to export 
the results for $\mathrm{E}$ xc el files, enterprise information management level. The Contract Manager can import the electronic version of the contract and related support materials systems, and easily accessible.

- The system automatically integrated: integrated management system contract stamp duty on decals, the entry of the users of the system of contracts, modify, delete, query, such as the operation will be recorded in the system log, and improve the work efficiency.

- Clear rights management: system user rights management, such as the three permissions users can only view I entered the contract, two privileged users can browse all contracts, a privileged user to user management and system log management.

- $\quad$ Reminder: The system automatically daily e-mail alert will soon need to pay/receivables contract manager or the Finance Department.

The contract management system is a simple and friendly interface, easy operation, information-rich, and to meet the management needs to make the work efficiency and quality of synchronization. Figure1 is the main interface of the system.

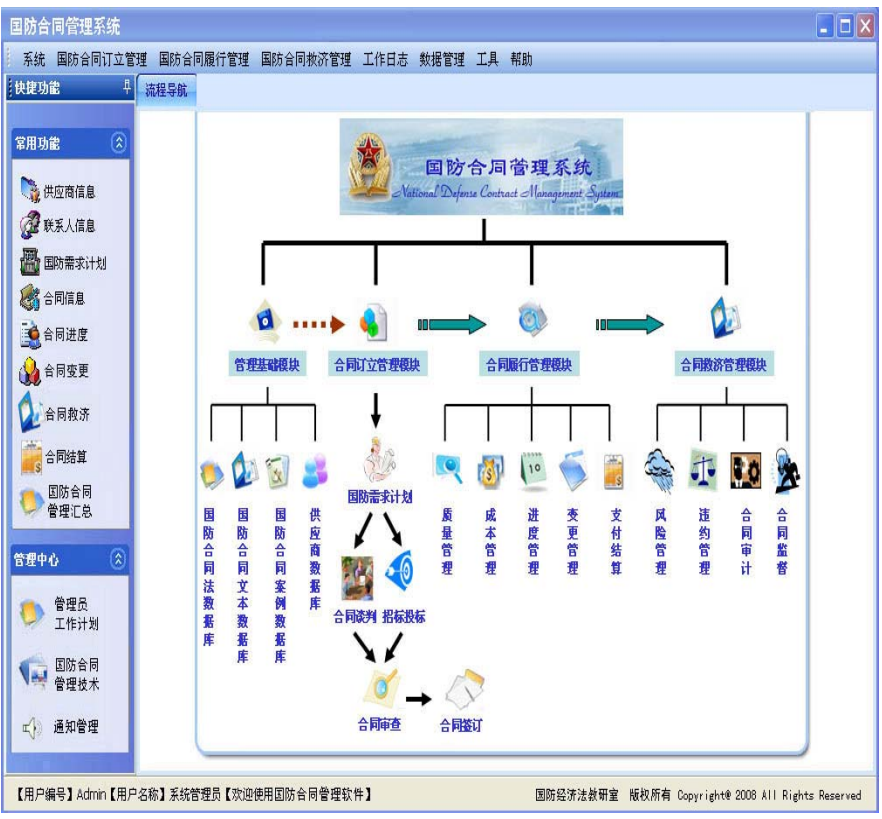

Fig.1

\section{SYSTEM DEVELOPMENT ENVIRONMENT}

\section{A. Choices of development tools}

ASP.net is a procedural framework based on the common language, a Web server can be used to build powerful Web applications. ASP. NET is compiled common language runtime code running on the server, ASP.NET can take advantage of early binding, real-time compiler, native optimization, and the box outside the cache service, which is equivalent to writing lines of code before they significantly improve the performance. ASP.NET framework complements the toolbox and designer in Visual Studio integrated development environment, and at the same time ASP.N ET with great power and flexibility, simplicity and manageability, scalability and availability, custom and scalability and excellent security. In this system the Visual Studio development environment, in the ASP.NET framework.

\section{B. The choice of database}

Microsoft Access has friendly interface, easy to use, the development of simple and flexible interface features, is an excellent desktop database management system. Its main features are as follows:

- Improve the management of a variety of database objects, has a powerful data organization, user management, security checks and other functions.

- multi-user database management system with powerful data processing capabilities in the network environment of a working group level, using Access development of the traditional the XBASE (the DBASE of FoxBASE collectively) client-server database systems can not be achieved (Client/Server) structure and the corresponding database security mechanisms, Access with the advanced large-scale database management system with characteristics such as transaction processing/error rollback capability.

- Can easily generate a variety of data objects, using the stored data to establish the forms and reports, visibility is good.

- $\quad$ As part of the off ice package can be integrated with the Office, seamless connection.

- To take advantage of the Web retrieval and dissemination of data, with the Internet connection. Access is mainly applied to small and medium-sized applications or as a client database in a client/server system.

After analysis, the contract management system uses a database includes a few dozen tables, is a small relational database, and maintaining neither information nor how complex the system, Access is a good tool for database development.

\section{SYSTEM FUNCTIONAL DESIGN}

\section{A. The entry of basic information}

Entry and modification of the basic information of the contract, including the time of signing the contract, contract number, contract name, the name of the contracting parties, our managers, contract amount, contract type, whether the receivables contract. Figure contract information into the interface.

\section{B. The execution of the contract management}

Entry and modification of the system in a timely manner stipulated in the contract and the progress of the actual pay/receive payments, including the contract to pay/number of the Receiving, each pay/receivables percentage of the contract, the actual pay/number of the Receiving and pay/closing time of payment, amount of the payment application is complete to apply for the completion of an invoice, invoicing is complete, pay/closing section is complete. The system according to the application of the payment is complete to apply for the completion of an 
invoice, invoicing is complete, pay/closing section is complete to automatically determine the next pay/section of the timing and amount as well as all pay/receive payments completed.

\section{Validity check}

The system can be required to check and validity check for entry information and modify the contract. For example, the date must comply with the prescribed format and the amount must be positive.

\section{Tax Review}

The person in charge of Finance Department Tax can be set and see if the contract needs and whether or not affixed the stamp duty, as well as tax and stamp duty amount, stamp duty on the total amount.

\section{E. Automatic calculations}

The system according to the contract amount and contract the actual pay/receive payments automatically calculate the contract amount paid and the unpaid amount.

\section{F. Progress to remind}

The systems will automatically a day for all contract records for a scan. For the next pay/income section 3d within the expired contract, if the payment contract, the system will remind the contract entered by mail to complete the payment application, or to remind the Finance Department to complete the payment; receivables contract, the system will complete the application for invoicing via e-mail alerts contract entered or to remind the Finance Department to complete an invoice or completion of receivables.

\section{G. Completion of the contract to remind}

Users to modify the contract to pay/closing paragraph of information makes the contract all pay/receive payments completed, the system will automatically send e-mail notification of contract entry and Finance Department of this contract have been completed to pay/income models.

\section{BENEFIT ANALYSIS}

\section{A. Dynamic monitoring of the implementation of the contract}

The system stores all the critical data associated with the contract, through a variety of remind, warning feature set, contract monitoring, real-time monitoring and the implementation of the contract is automatically formed record. For example: to view payment/collection contracts to remind or warn the user that the next operation, to make your business more profitably.

\section{B. Standardized and transparent contract management workflow}

The system has set up three user rights, provides for different levels of user functionality in the system, thus simplifying the functions of various positions in the contract management process, the provisions of its unique functions, responsibilities, such as the average user can only browse the data of the respective departments of the contract allows each user to be able to carry out their duties, to avoid human intervention and the powers and responsibilities of an unknown phenomenon.

\section{Improve the work efficiency, reduce operating costs}

System applications, business can be simple operational data access related business status inquiries and other daily work. Leadership personnel can be easily carried out a variety of business inquiries, export query results. To get rid of the shackles of the original manual for the staff at all levels, greatly improved work efficiency, ease of entry can also be the case even in the absence of professional backgrounds. In short, the system of contract management of information, intelligence, unified, to reduce unnecessary human and material resources, and greatly reduced the company's operating costs.

\section{Business operations have documented}

The system log records the user's entry on the contract, modify, delete, query, and on almost all business operations are left to record for later viewing. This effectively avoids the responsibility can not distinguish between the problem and can be easily understood that the contract changes to the data recorded.

\section{REFERENCES}

[1] Xiong Xiaoxu,Ding Yujun,Zhang Limei.Research on the feasibility of MIS in the mode of explorer-server[J].Applied science and technology, 2000,27(9):30-34.

[2] Ge Wuxiang,Chen Zhigang. The design for a distributed system based on the three-layer browse/server model[J].Computing technology and automation,2004,23(3):73-75.

[3] Liu Yuyan.Make use of ASP and ADO technology to visit database [J] .Computing technology and automation, 2001,20(1):39-41.

[4] Wu Ping,Pu peng. Design and application of Online Testing Platform based on the $\mathrm{B} / \mathrm{S}$ structure Microcomputer applications, 2003,19(6):36-38. 